\title{
Hohe Zugriffszahlen auf die neue Homepage durch Patienten und Ärzte
}

Nachdem der Vorstand der Deutschen Gesellschaft für Phlebologie vor über einem Jahr die Neugestaltung der Homepage beschlossen und diesem Projekt hohe Priorität eingeräumt hat, ist die neue Homepage der Deutschen Gesellschaft für Phlebologie seit Februar dieses Jahres online.

Fast $50 \%$ aller Mitglieder mit einer eigenen E-Mail-Adresse haben sich derzeit im Mitgliederbereich bereits angemeldet und sich auf der neuen Homepage eingeloggt. Das Feature der „Arztsuche“ nutzen derzeit ca. 160 Praxen und Kliniken. Seit OnlineStellung bewegt sich die Zahl der Zugriffe auf unsere Homepage bei über 15000 Besuchern pro Monat. Dabei ist die Zahl der Seitenansichten seit März 2019 bis Juli 2019 von 30000 auf über 45000 gestiegen.

Der überwiegende Zugriff erfolgt über mobile Endgeräte. Hier zeigt sich, dass die Entscheidung, bei der Gestaltung der Webseite diese insbesondere für mobile Endgeräte zu optimieren, der richtige Weg war. Die Konzeption einer zweigeteilten Webseite mit einer speziellen Ansprechseite für $\mathrm{Pa}$ tienten und einem Teil für Ärzte hat sich sehr bewährt, da die Zugriffszahlen durch die Patienten extrem hoch sind und hier als Key-Feature insbesondere die Arztsuche genutzt wird.

Die Arztsuche erlaubt es und erfordert von den Mitgliedern, ihren Praxiseintrag selbstständig zu pflegen, Informationen zu Öff-

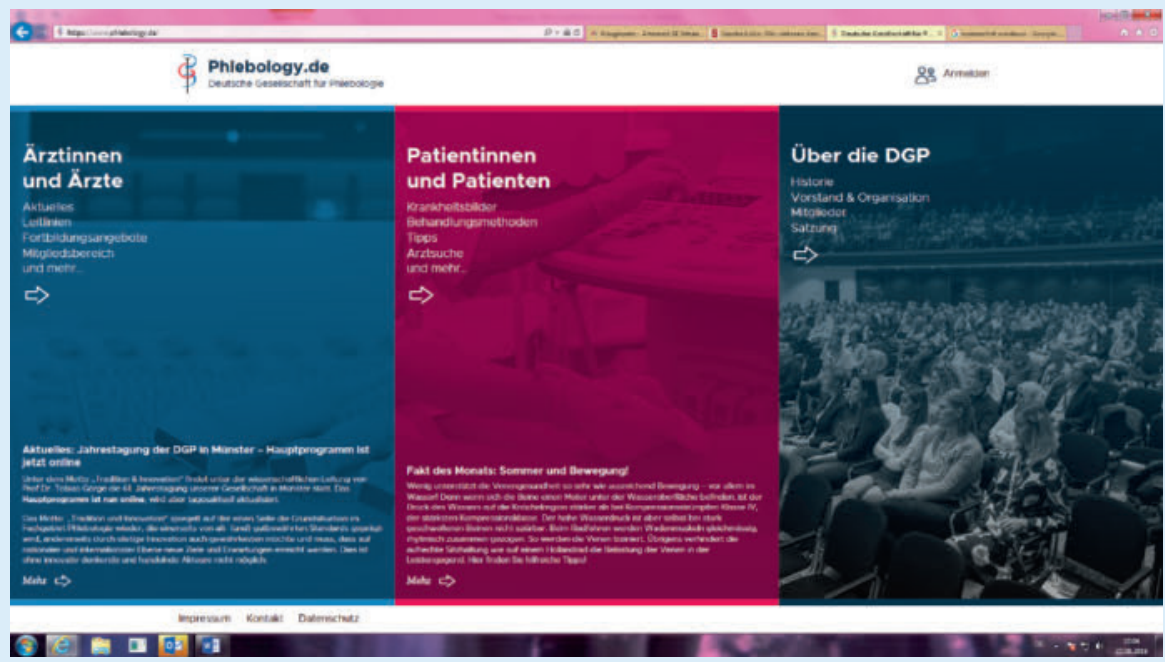

nungszeiten und Behandlungsmethoden zu ergänzen bzw. aktualisieren und weitere Praxisstandorte hinzuzufügen. Wir können hier nur allen Mitgliedern empfehlen, sich mit ihrer Praxis zu positionieren und den Eintrag im Mitgliederbereich der Homepage unter „Meine Arztsuche“ zu aktivieren. Die Webseite gibt Ihnen hier ein wertvolles Tool der Eigenwerbung an die Hand.

Wir alle, die wir Zeit und Mühe in die Webseite investiert haben, freuen uns über den entstandenen Erfolg und auch die Tatsache, dass das in die Hand genommene Geld gut investiert worden ist.

Unsere Homepage bietet Ihnen als Mitglied einen echten Mehrwert und für unsere Patienten Online-Informationen auf dem neu- esten, qualitativ hochwertigen, für Patienten verständlichen Stand.

Die neue Webseite bietet der Deutschen Gesellschaft für Phlebologie die Möglichkeit, auf die Zugriffsdaten der Nutzer zuzugreifen, um kontinuierlich die Webseite zu verbessern und unseren Mitgliedern Empfehlungen, zur eigenen Wahrnehmung für die Patienten zu geben. Es zeigt sich, dass das Feature „Arztsuche“ für die Patienten einer der bedeutendsten Bestandteile dieser Hompage ist.

\section{Dr. Guido Bruning}

Wissenschaftlicher Beirat der DGP AG Webseite der DGP 